\title{
Visión y acción de Washington frente a la deuda externa latinoamericana
}

La intención del presente trabajo no es, en modo alguno, ofrecer una historia completa y detallada de la deuda externa latinoamericana. Se trata más bien de partir de su actual volumen, tendencias y perspectivas, para ubicarla en el ámbito más concreto de las reacciones que el problema provoca en el seno de las autoridades financieras internacionales que operan en Washington, D. C.: el Fondo Monetario Intemacional y el Banco Mundial, principalmente. Se intenta también poner de manifiesto el punto de vista de las más importantes autoridades financieras norteamericanas: el Tesoro y el Sistema de la Reserva Federal. Finalmente, se quiere, igualmente, introducir la visión de la banca privada internacional, en general, y de la estadounidense en particular, por ser ella la principal acreedora de la región, así como la reciente concertación de sus esfuerzos para enfrentar las dificultades planteadas por la descomunal deuda externa del mundo en desarrollo, dentro de la cual destaca por su magnitud la latinoamericana, vía la formación de una especie de "trilateral de acreedores", según puede desprenderse del establecimiento, en enero del presente año, del Instituto de Finanzas Internacionales en la propia ciudad de Washington, también.

Quizás vale la pena empezar esta sección señalando que, en la década de los años setenta se registra un importante cambio en el sistema financiero internacional que va a tener un impacto directo sobre el volumen de la deuda externa de América Latina, sus tendencias y algunas de sus consecuencias actuales. Se trata de la impresionante transformación registrada al nivel de las fuentes de financiamiento externo disponibles para la región.

Puede decirse que hasta finales del decenio de los años sesenta, la inversión extranjera directa era la principal fuente de recursos procedentes del exterior. A partir de los años setenta, sin embar- 
go, esta situación se modifica radicalmente y son los préstamos, fundamentalmente los de tipo comercial, los que pasan a adquirir primacía. Así, mientras que en los períodos 1960-1964 y 1965-1969 la inversión extranjera directa representó el 47,0 y el $56,5 \%$ respectivamente, de las corrientes de capital externo canalizadas a la región ${ }^{1}$, para el período $1971-1973$ este porcentaje había descendido al 24,4 y en 1974-1980 sólo representó, aproximadamente, el 18,0\% de las corrientes totales ${ }^{2}$.

Tan radical modificación del financiamiento externo de la región a favor del endeudamiento y en contra de la inversión directa, constituyó un fiel reflejo de lo que sucedía a nivel mundial: el surgimiento y acrecentamiento de una oferta excesiva de capitales en los mercados internacionales de dinero, lista a ser canalizada en forma de préstamos, principalmente por los grandes bancos transnacionales.

Dos son los fenómenos explicativos más importantes del surgimiento y afirmación de esa liquidez internacional excesiva. En primer Iugar, habría que mencionar la recesión, que en la esfera de la producción de los países industrializados se registra en los años setenta: el dinero que no es invertido en la esfera productiva es desplazado a la bancaria, buscando su colocación por la vía de la intermediación financiera a fin de asegurar su mayor rentabilidad posible. En segundo lugar, esa liquidez excesiva se acrecienta aún más a partir de 1973, y la llamada "crisis energética" y posteriormente en $1979 \mathrm{y}$ el "segundo choque petrolero", en virtud del reciclaje de los petrodólares, originados en las revaluaciones de los energéticos, a través del sistema financiero internacional. No en balde el mercado de euromonedas, cuyos orígenes datan de la segunda postguerra, pero que alcanza su verdadera dimensión en los años setenta, en tanto que reciclador por excelencia de esa oferta excedentaria de liquidez, pasa de 14.000 millones de dólares netos en 1964, a 50.000 millones en 1969, a 155.000 millones en 1973 y a 600.000 millones en $1979^{3}$.

Esa oferta excesiva de recursos tuvo un impacto inmediato e im-

'Lecuona y Serrato, "Deuda externa de América Latina". Revista de Economia de América Latina", México, Centro de Investigación y Docencia Económica, No $1,1978$.

${ }^{2}$ Banco Interamericano de Desarrollo, Progreso Económico y Social en America Latiria EI sector externo. Informe 1982, Washington, D. G., 1982, p. 61.

${ }^{3}$ Green Rosario, Estado y banca transnacional en México. México, GeEsten, Editorial Nueva Imagen, 1981, p. 188. Si bien el euromercado siguió creciendo, y en septiembre de 1981 reportó un volumen neto de 855.000 millones, su expansión a las tasas anteriores se ha visto frenada conforme los superávit de un buen número de países miembros de OPEP han ido desapareciendo con las recientes bajas de los precios del crudo. 
presionante sobre la ya de por si significativa demanda de capitales de los países' en desarrollo, estimulándola aún más. Provistos de liquidez sin precedentes, los bancos internacionales se lanzaron a la búsqueda de nuevos clientes, dando lugar a una feroz competencia interbancaria, que habría de reflejarse inciusive en una serie de presiones sobre los usadores de fondos. Los términos de los préstamos se flexibilizaron, y países antes sin acceso a estos 'capitales empiezan a ganario rápidamente y a utilizarlo como sustituto a la implantación de un buen número de reformas internas que pudieran hacer menos gravosa la dependencia de estas economías respecto del capital extranjero.

A la luz de esta situación, la explicación tradicional que plantea el crecimiento de la deuda externa de un país en función exclusivamente de su demanda de recursos para hacer frente a sus desequilibrios internos (I-S) y externos $(\mathrm{X}-\mathrm{M}$ ) , debe ser repensada. La oferta abundante de recursos llegó a desempeñar un papel también central, de forma que en la esfera financiera, como en la de la producción, puede sostenerse que a través de cierto tipo de mecanismos, que van desde la propaganda hasta las presiones de los banqueros, la oferta de recursos va, si no a generar su propia demanda, al menos sí a acrecentarla.

Los gobiernos y sectores públicos ' $y$ en ocasiones inclusive los privados) de los países en desarrollo que aparecen como clientes ideales de los banqueros internacionales armados con liquidez, empezaron a operar sobre el falso supuesto de que tal disponibilidad de recursos externos en forma de préstamos, en condiciones inclusive ventajosas en tiempos de inflación mundial -que redundaba en tasas reales de interés bajas y hasta negativas- era sinónimo de que sus problemas y aspiraciones de crecimiento podían encontrar solución en una oferta de dinero infinitamente elástica en los mercados internacionales.

Como una primera consecuencia de ese tipo de creencia, el endeudamiento externo se convirtió en el mecanismo de ajuste ideal, que permitía corregir los desequilibrios de estos países sir necesidad de alterar su estructura política interna, las correlaciones de fuerza o los sistemas de privilegios.

Una segunda consecuencia fue, necesariamente, la acelerada expansión del endeudamiento externo del mundo en desarrollo, dentro del cual América Latina ocupa el "lugar de honor", y el surgimiento y afianzamiento de ciertas tendencias de ese endeudamiento que, por cierto, persisten hasta la actualidad. Si la deuda externa del Tercer Mundo pasa de 40.000 millones de dólares en 1970 a 626.000 millones en 1982, según la OECD, la deuda latinoamericana rebasa en el presente a los 300.000 millones de dólares; representando, en todo caso, la mitad del total. 
Como sería de esperarse, tal expansión del endeudamiento externo no se da sin consecuencias. Una de ellas, tal vez la de mayor importancia, es el crecimiento de su servicio. Es un hecho que el servicio de la deuda externa del mundo en desarrollo ha crecido más que su monto absoluto. Esto es especialmente cierto a partir de 1977, cuando los pagos por servicio (interés más amortización) aumentaron en un 43\%, manteniendo Iuego tasas nominales de expansión superiores al $30 \%$, como reflejo tanto de la tendencia al alza de los intereses, nominales sostenida hasta muy recientemente, como del tradicional acortamiento de los plazos y el peso de otro; cargos notablemente los diferenciales o "spreads" que miden el riesgo país

Para América Latina, la carga por servicio de su deuda externa representaba en 1981, el $30 \%$ de sus ingresos de exportaciones, y el $81 \%$ de los desembolsos.recibidos ese $a n ̃ o^{5}$. A finales de 1982, tan sólo Argentina, Brasil y México tenían que pagar 60.000 millones de dólares de intereses y amortizaciones, es decir, casi un tercio de su adeudo total, calculado en 200.000 millones de dólares. Y si a esto se agrega el que en la actualidad, prácticamente todos los países de la región han hecho públicas sus dificultades crecientes para satisfacer sus compromisos con el exterior, el supuesto carácter "financiador" y aún "asistencial", que en el pasado se le asignó al capital extranjero, acaba siendo fuertemente cuestionado. Hoy día, un número importante de países latinoamericanos ha caído en un comportamiento vicioso, que proyecta un desfinanciamiento y aún un decrecimiento económico. Si en el pasado esos países se endeudaron externamente para crecer, en el presente parecen estar condenados a dejar de crecer para pagar sus deudas externas, ajustando sus economías a programas estabilizadores que lejos de resolver sus problemas estructurales y de mediano y largo plazos, someten a sus poblaciones a duros sacrificios, convirtiéndose en peligrosas fuentes de tensiones políticas y sociales.

Además del problema de la expansión creciente de la deuda externa de los países del Tercer Mundo y, en ella, de la latinoamericana, y de su cada vez más gravosa carga por concepto de su servicio, está la cuestión, ya apuntada, de sus tendencias. Es un hecho que al tiempo que esa deuda se ha expandido, se ha hecho cada

"En diciembre de 1978, la tasa "prime" (la del mercado norteamericano) había alcanzado $11,75 \%$ en diciembre de 1979 : fue de $15,25 \%$; en diciembre de $1980,21,50 \%$; en diciembre de 1981, 15,75\%; y en julio de $1982,16,50 \%$. La tása "libor" (la que priva en el mercado de Londres, sede del euromercado), pasó de $11,50 \%$ en diciembre de 1978 , a $18,00 \%$ en diciembre de 1979 , a $15,00 \%$ r en diciembre de 1980 , a $14,93 \%$ en diciembre de 1981 y a $15,28 \%$ en julio de 1982.

José Thiago Cintra, "Usura internacional". Excelsior, agosto 13, 1982.

'Estimaciones de la cepal. 
vez más privada en su origen y crecientemente controlada por los grandes bancos' transnacionales. En ese sentido puede afirmarse que dicha deuda se ha "privatizado" y "bancarizado".

La tendencia a la privatización de la deuda externa de América Latina queda de manifiesto por el hecho de que mientras que para 1961, por ejemplo, el $52 \%$ de la deuda externa total de la región se encontraba contratada con fuentes oficiales de financiamiento: instituciones multilaterales y bilaterales, y el resto $(48 \%)$ con fuentes privadas: proveedores, bancos y bonos, en 1980 esos porcentajes eran: $23,2 \%$ oficial y $76,8 \%$ privado, con casos extremos como el brasileño $\mathrm{y}$ el mexicano, sobre todo, donde el componente privado de la deuda pública externa superaba al $80 \%{ }^{6}$. Es interesante notar que esta privatización es más intensa en América Latina que para el promedio del mundo en desarrollo, donde las proporciones en 1979 eran 45 y $55 \%$, respectivamente, lo que muestra que la región era percibida como "más madura y menos riesgosa" tal vez, que el resto del Tercer Mundo.

Es cierto que la "privatización" de las fuentes de financiamiento externo tuyo para América Latina la ventaja de poner a disposición de un buen número de países cantidades crecientes de recursos, marginando al mismo tiempo y en cierto grado una fuente importante de injerencia en los asuntos internos de esas naciones, que ni siquiera representa, en muchos casos, condiciones financieras especialmente atractivas. Es un hecho que instituciones como el Banco Mundial, el Banco Interamericano de Desarrollo, la Agencia para el Desarrollo Internacional (norteamericana) en su momento, etc., no sólo ofrecen cantidades insuficientes de recursos sino que además el volumen prestado está denominado en una canasta de monedas duras, imponiéndose sobre el pafs prestatario la asunción del riesgo cambiario, así como la observancia de una serie de reglas conșideradas sagradas por las instituciones prestamistas: préstamos para proyectos específico, supervisión constante, adopción de medidas de política económica no siempre populares, etc. Sin embargo, no puede alegarse que al contrario de las instituciones oficiales, las fuentes privadas de financianiento hayan puesto a la disposición de los países de América Latina sus mayores volúmenes de recursos sin injerencia alguna y en condiciones siempre favorables. Ya se señaló que estas instituciones ofrecen en general créditos sujetos a tasas de interés altas y flotantes y a plazos de amortización que han tenido a reducirse, con las consabidas repercusioses sobre la çarga del servicio de la deuda. Además, desde una perspectiva

${ }^{8}$ Datos para 1961: Banco Interamericano de Desarrollo, Deuda pública externa de los paises de América Latina. Washington, D. G., julio 1981. Datos para 1980: Banco Mundial, World Debt Tables. Washington, D. C., 1982. 
macroeconómica, no parece demasiado arriesgado sostener que las instituciones privadas de financiamiento están también en condiciones de emitir su. voto, así sea de manera indirecta, sobre el modelo de crecimiento de los países, favoreciendo, como es de esperarse, aquellas características, como la mayor apertura e internacionalización de la economía, que garantizan la generación de divisas para servir compromisos financieros adquiridos, al margen inclusive de estrategias nacionalistas o consolidadoras de la industria nacional.

Por lo que toca a la bancarización, ésta se pone de manifiesto si se aprecia que mientras que en 1961, los bancos proporcionaban solamente el $30 \%$ de todos los créditos canalizados a América Latina, para 1980 esta proporción era ya de $52 \%$. De nuevo, se dieron casos como el brasileño $y$, muy particularmente el mexicano, en los que el financiamiento bancario superaba el $90 \%$ del financiamiento privado. Una vez más, la bancarización para América Latina resultó superior al promedio para el mundo en desarrollo, donde la proporción para 1979 era de $41,5 \%{ }^{7}$.

Al igual que la privatización, la bancarización ha tenido sus ventajas para la región, en especial porque ha marginado considerablemente a los créditos de proveedores, importante fuente de recursos en el pasado, pero sumamente atados. Sin embargo, la bancarización de la deuda externa de América Latina ha implicado también sus desventajas. El mayor costo del dinero, incluido el costo de la incertidumbre debido a la práctica de tasas de interés flotante es tan sólo una de ellas. Está también la sujeción de los destinos nacionales" a la buena voluntad de los banqueros y a su supervivencia en tiempos de sobreexposición, crisis internacional y controles nacionales en sus países de origen. Por último, debe mencionarse también el hecho de que al bancarizarse, la deuda externa de la región se ha hecho más inestable, volátil y especulativas.

Finalmente al lado de estas dos tendencias ampliamente reconocidas y en franca expansión, está toda la cuestión de la "norteamericanización" de la deuda externa de América Latina, o sea, del peso que en el financiamiento privado y bancario que recibe la región, tienen las fuentes norteamericanas.

Durante el siglo xrx, la exportación de capitales a países en de-

'Idem.

Una serie de casos de estudio sobre la actuación política de los bancos internacionales puede encontrarse en: Estevez V. y Samuel Lichtensztejn (compiladores), Nueva fase del capital financiero. Elementos teóricos y experiencias en América Latina. México, ceestem.Nueva-Imagen, 1981. Para el caso de Perú ver, además: Devlin, Robert, Transnational Banks and their Penetration of the External Finance of the Third. World: the experience of Pert, 1975-1976. Santiago. CEPAI, 1978. Consultar, también, Devlin, R. Los bancos transnacionales, el Estado y el endeudamiento externo en Bolivia, Santiago, CEPAI, 1982 (mimeo). 
saurollo se encontró dominada en buena medida por. Inglaterra, y se caracterizó por flujos de origen privado y préstamos que tomaban la forma de emisiones de bonos. Esta actividad se dirigió por primera vez a América Latina en 1820, con la aparición de Colombia como prestatario y se generalizó a partir de 1822, dando lugar al advenimiento de los que habrian de ser los países más endeudados de la región. Así, entre 1862 y 1867, por èjemplo, los préstamos gubernamentales para América Latina emitidos en Londres sumaban ya un total de 40 millones de libras esterlinas, siendo los principales deudores Perú, Brasil, Venezuela y México. Para 1914, el grado de compromiso de algunos países latinoamericanos con Inglaterra había alcanzado niveles tan altos que, unidos a otras dificultades a las que el capitalismo inglés se enfrentaba, llevaron a un retraimiento de la actividad exportadora de capitales de la nación. En ese momento, las inversiones emitidas públicamente en Londres hacian un total de casi 4.000 millones de libras esterlinas, de los cuales 756 millones estaban en manos de países de América Latina: Argentina a la cabeza con 320 millones, Brasil con 150 y México con $100^{9}$.

Conforme la hegemonía mundial inglesa se resquebrajaba en innumerables sitios, el papel de Estados Unidos como eventual potencia sustituta se afianzaba. Ya para 1930, Estados Unidos rivalizaba con Inglaterra en volumen de capital exportado y dejaba sentir el peso de su poderío industrial y mercantil. No resulta extraño, entonces, que para 1960, el $60 \%$ de todas las inversiones de las grandes potencras en el extranjero fuera de origen norteamericano, ni que para mediados del decenio de los años setenta cerca de las tres cuartas partes de todas las operaciones de préstamos a nixel mundial (y cerca del $50 \%$ de las canalizadas at unundo en desarrollo) pudieran ser atribuidas a iuentes estadounidenses, princıpalmente bancos privados.

La fuerza de la presencia de los bancos norteamericanos en América Latina fue siempre, por razones históricas y estructurales, más impactante ahí que en otras regiones del mundo. Desde sus primeros contactos con la zona, los grandes bancos estadounidenses se dedicaron a colocar bonos de gobiernos latinoamericanos, cuyos títulos emitidos en Estados Unidos entre 1898 y 1914 sumaron 236 millones de dólares. Entre 1915 y 1935 aumentaron en más de diez veces, a 2.672 millones. Los bancos norteamericanos buscaron extender sus contactos en el área mediante la apertura de sucursales, que en 1925 sumaban 50 en América Latina, la mayoría de las cuales se ocupaba del financiamiento al comercio con Estados Unidos.

Los flujos de capital fueron interrumpidos durante la Primera

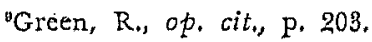


Guerra Mundial, pero luego se aceleraron rápidamente, comandados por el surgimiento del mercado neoyorquino como principal centro financiero, aunque Londres sigue siendo hasta la fecha el lugar donde la gran banca transnacional desempeña un papel clave. Esto generó una dura competencia bancaria entre Estados Unidos e Inglaterra, lo que agravó las consecuencias mundiales de la crisis de 1929.

A principios de la década de los años treinta se presentaron en América Latina incumplimientos en serie, prologados por Bolivia en 1930, seguidos por Perú, Chile y Brasil en 1931, y por Uruguay, Colombia y algunos países centroamericanos en 1932. México, por su parte, se encontraba en esa situación desde su revolución de 1910 y prolongaría su moratoria hasta principios del decenio de los años cuarenta. Para 1933, casi todos Ios países latinoamericanos declararon moratorias, agobiados por el peso de su enorme deuda externa; el $67 \%$ de las emisiones de bonos estaba en quiebra.

Debido en gran parte a la emisión especulativa, comportamiento inadmisible a los ojos de los inversionistas extranjeros, los paises en desarrollo vieron restringido su acceso a los mercados crediticios internacionales, que fueron duramente regulados para limitar la compra de bonos latinoamericanos. A tal punto que entre 1930 y 1960 su circulación en Estados Unidos se redujo drásticamente. En los años sesenta, solamente se emitieron bonos por 603 millones de dólares, de los cuales correspondieron a México 383 y a Argentina $107^{10}$.

Flujos complementarios provinieron de instituciones financieras y agencias norteamericanas e internacionales, pues los bancos comerciales sólo volvieron a ser importantes hasta los años setenta.

Es un hecho que en el pasado decenio la banca privada norteamericana se establece como la banca transnacional por excelencia. Para 1975, por ejemplo, los bancos estadounidenses monopolizaban el $38,2 \%$ de las operaciones del mercado de euromonedas. Para ese mismo año también, tres de los diez mayores bancos del mundo eran norteamericanos: el Bank of America, siendo el número uno a nivel mundial, el Citicorp como número dos y el Chase Manhattan en el cuarto lugar. Para 1975, también, el 27,3\% de todos los activos de todos los bancos transnacionales era de origen norteamericano, representando el porcentaje más elevado en términos de nacionalidades. Igualmente, para 1975, ya se dijo, cerca de la mitad de los créditos proporcionados a países en desarrollo era capital estadounidense, y ese era el origen de más de la mitad de los préstamos latinoamericanos ${ }^{11}$.

10Idem, p. 204.

${ }^{11}$ Idem, pp. 196.197. 
La banca transnacional estadounidense ha mantenido un grado mayor de concentración de sus préstamos en los países subdesarrollados no miembros de la OPEP, que el conjunto de todos los ban$\cos$, favoreciendo así a la región latinoamericana a la que, tradicionalmente, los agentes oficiales y privados norteamericanos han considerado como su área de influencia natural. Dentro de ella algunos países resultaron también más atractivos que otros: la mitad de los créditos canalizados por la banca transnacional norteamericana al mundo en desarrollo a mediados del decenio pasado tuvo como destinatarios a Brasil y México. En estos dos países tienen en la actualidad invertidos los nueve bancos norteamericanos más importantes, el $85,1 \%$ de su capital total: $44,3 \%$ en México y $40,8 \%$ en Brasili2.

En los últimos años del decenio pasado, sin embargo, se nota un descenso en la participación de la banca transnacional norteamericana en el mundo en desarrollo y una relativa "desnorteamericanización" de la deuda externa latinoamericana. Los bancos europeos y japoneses aprovecharon para afianzar su presencia en los paf́ses subdesarrollados, la relativa retirada de los estadounidenses provocada fundamentalmente por un ligero incremento de la demanda norteamericana de capitales y por consideraciones que tuvieron que ver con niveles de ganancia inferiores a los esperados. Aparentemente los bancos norteamericanos asignan al factor utilidad el vaIor prioritario por excelencia, y el hecho de que ante el surgimiento de niveles crecientes de liquidez internacional a los que se hizo referencia páginas atrás, la abundante oferta contribuyera a abaratar el precio del dinero, desalentó en cierta medida la actividad de los bancos estadounidenses en el exterior (y más que nada en los países del Tercer Mundo, algunos de los cuales como Zaire, Turquía, Perú, empezaban a mostrar signos de dificultades financieras), pese a que en años pico de actividad internacional, como en 1975 por ejemplo, el $47,7 \%$ de las utilidades totales de los trece bancos más importantes en Estados Unidos se originó en el exterior. Los bancos japoneses, por su parte, y también un buen número de los europeos parecen (por lo menos así se percibía a finales de la década pasada), más dispuestos a priorizar sus metas de manera algo diferente. Sin dejar de reconocer la importancia de sus utilidades, asignan igual valor a los aspectos colaterales de su financiamiento: la promoción de su comercio exterior, la garantía de un clima adecuado para sus inversiones, la diseminación de su tecnología, etc., lo cual les permitió en un determinado momento aceptar menores

12Washington Post. Octubre 24, 1982. 
tasas de ganancia que las esperadas y llenar el vacio relativo que dejaba la banca norteamericana ${ }^{13}$.

Ast, para 1978, si bien tres bancos norteamericanos figuraban entre los diez mayores del mundo, y el Bank of America seguía siendo el número uno, el Citicorp venía en tercer lugar y el Chase en el último. Para 1979, la participación relativá de la banca norteamericana en el total de reclamos existentes de la banca transnacional sobre los países en desarrollo pasó de haber representado cerca del 50\% en 1977, a significar el 37\%. Para países concretos de América Latina se registró un descenso igualmente importante. En los seis mayores prestatarios latinoamericanos no miembros de la OPEP, la banca norteamericana pasó de representar en 1977 el $57 \%$ de los reclamos bancarios mundiales totales a constituir tan sólo el 42\%; con casos tan graves como el argentino, donde dicha banca pasó del $61 \%$ al $38 \%$; el mexicano, donde se pasó del $60 \%$ al $42 \%$ y el colombiano, del $75 \%$ al $59 \%$. En la actualidad, la relativa "desnorteamericanización" de la deuda externa de América Latina se ha afianzado aún más, pero las cifras que la reflejan no han podido desmentir el peso real de esa banca para la región; es un hecho que ésta sigue isendo hegemónica y su reciente participación en las crisis de deuda que caracterizan al panorama económico latinoamericano de los años ochenta es una realidad a la que se dedicará mayor atención más adelante en este trabajo.

La creciente importancia de las fuentes de financiamiento privado y bancario (y norteamericanas) para América Latina (y el Tercer Mundo en general), se vio acompañada, por lo menos hasta hace muy poco, de una importancia también creciente de la región (si bien no simétrica ni homogénea), en los mercados de dinero. Concretamente se ha registrado un fenómeno de "tercermundización" y "latinoamericanización" del mercado de euromonedas muy claro por lo menos hasta el término del decenio pasado, menos claro tal yez en el actual, que vale la pena caracterizar.

Hasta 1969, los principales usuarios del crédito internacional eran los bancos norteamericanos, que comenzaron a salir masivamente al exterior, como consecuencia de los controles a la exportación de capitales que las autoridades en Washington implantaron a partir de 1963. El Gobierno del Presidente Kennedy gravó los préstamos al extranjero, el de Johnson impuso controles a la salida

: ${ }^{2}$ Centro de Naciones Unidas sobre Corporaciones Transnacionales TransnaLional Banks: Operations and Strategies and therr Effects on Developing Countries. Nueva York, 1980 (mimeo).

${ }^{14}$ Green, R. op, cit., p. 202. 
de capital productivo y bancario y el de Nixon los mantuvo hasta 1974.

La meta de esos controles era reducir las masivas salidas de dólares desde Estados Unidos y mejorar la situación de la balanza de pagos norteamericana que se deterioraba sensiblemente. Sin embargo, su impacto fue, en el corto plazo, insignificante, y resultó, a la larga, contrario a lo esperado y devastador: las exportaciones de capitales, lejos de reducirse, se incrementaron notablemente, en realidad, pero de manera disfrazada. De 1964 a 1974, los bancos norteamericanos salen masivamente al exterior. En 1965 sólo ll bancos tenían sucursales en el exterior, las cuales sumaban 211. En 1975 ya eran 126 los bancos norteamericanos con sucursales fuera de sus fronteras, y éstas sumaban 762; su predominio financiero era tal que, ya se señaló en repetidas ocasiones aquí, en términos generales estos bancos y sus sucursales controlaban, a mediados del decenio pasado, más de las dos terceras partes de todos los préstamos a nivel mundial; porcentaje que por cierto empezó a descender en los últimos años de ese decenio, al tiempo que avanzaba la penetración de la banca europea y japonesa, pero que nunca perdió del todo su hegemonía.

La impresionante sucursalización internacional de la banca norteamericana tuvo como principal finalidad, habilitarla para poder seguir a sus importantes clientes: las grandes empresas transnacionales de origen norteamericano. Conforme dichas empresas se hicieron cada vez más autofinanciables, disminuyeron sus necesidades de recursos externos, y empezaron a ganar importancia en el mercado los sectores públicos (y hasta privados) de otros países industrializados. Sin embargo, y según se apuntaba páginas atrás, al presentarse la recesión en la esfera productiva, característica de los años setenta la demanda del mundo desarrollado por recursos provenientes de los propios países industrializados cedió, y aparecieron los países en desarrollo como prestatarios de importancia si bien en los tiempos más recientes, los países desarrollados han vuelto a adquirir primacia (aunque las operaciones interbancarias siguen siendo las fundamentales).

Se insiste que la emergencia del Tercer Mundo en el euromercado se explica en virtud de factores ya mencionados como, en primer lugar, la creciente necesidad de recursos financieros (donde, como es de suponer, el impacto de aquellos destinados a pagar por las importaciones de hidrocarburos a precios crecientes, fue fundamental) y la imposibilidad de satisfacerla con base exclusivamente en los de carácter oficial (o aún con inversión directa, sobre todo en condiciones de recesión productiva en los países industrializados). En segundo lugar, la acelerada formación de una liquidez excesiva en el mercado de euromonedas, conectada a la recesión 
mumdial, pero exacerbada por el reciclaje de los petrodólares. En tercer lugar, las presiones ejercida por los banqueros internacionales sobre los gobiernos de los países en desarrollo, a fin de colocarla rentablemente.

Ast, para 1975 los países subdesarrollados absorbían ya el $56,5 \%$ de la deuda en euromonedas de todos lós países del mundo, y si bien es cierto que ese porcentaje declinó ligeramente en los tres años siguientes, al incrementarse, ligeramente también, las demandas de fondos de los países desarrollados, en todo caso siguió representado más de la mitad del total, llegando incluso a alcanzar la cifra record de $57,4 \%$ en 1979, año del segundo gran momento de expansión del euromercado (el primero siendo 1973-74), como consecuencia del nuevo aumento de los precios de crudo decretado por la OPEP15.

Recientemente, se señalaba, la participación del Tercer Mundo en el euromercado ha disminuido, debido principalmente a la saturación. de algunos de sus integrantes, especialmente de América Latina y, dentro de ella, de México, Brasil y Argentina, así como por un nuevo incremento de la demanda de países industrializados, $y$ porque la caf́da de los precios internacionales del crudo, en 1981, al reducir el ingreso petrolero esperado, redujo los volúmenes depositados por los países exportadores de petróleo en el euromercado, y por lo tanto, los eurocréditos ${ }^{16}$.

Ahora bien, independientemente de que el fenómeno de "tercermundización del euromercado en la década de los setenta es un hecho, esto no implica que todos los países en desarrollo tuvieron en él igual importancia. A finales de 1979. cerca del $80 \%$ de los eurocréditos estaba concentrado en quince países: México, Brasil, Corea del Sur, Venezuela, Argentina, Argelia, Filipinas, Irán, Indonesia, Chile, Marruecos, Emiratos Arabes, Malasia, Taiwán y Perú17. Además, tan sólo los seis países latinoamericanos del grupo representaban poco más del $50 \%$ del total canalizado a los países en desarrollo, por lo cual, ya se señalaba, es válido sostener que, en el pasado decenio, el euromercado, además de "tercermundizarse", se "latinoamericanizo".

Tan elevado grado de concentración de los eurocréditos canalizados al Tercer Mundo en unos cuantos deudores, encuentra buena parte de su explicación en la propia conducta de los prestamis-

\footnotetext{
${ }^{25}$ Cxuced, The Flow of Financial Resources, TD/B/C.3/150, septicmbre, 1978; oCDE, "Access by Developing Countries to International Financial Markets". Financial Markets Trend, No 18, 1980.

${ }^{10}$ Morgan Guaranty Trust Company of New York, World Financial Markets, octubre, 1982.

${ }^{27}$ Jeff Friedm, Third World Indebted Industrialization: international finance and State capitalism is Mexico, Brazil, Algeria and South Korea". International Organization, vol, 35, No 3, verano, 1981.
} 
tas. Es un hecho que los banqueros que operan en el mercado de euromonedas y prestan a los pafses en desarrollo prefirieron a los "petroleros" (productores y exportadores de importancia), En segundo lugar, favorecieron a los países relativamente grandes y de "altos ingresos". En tercer lugar, prefirieron también a aquellos con regimenes políticos "estables", con economlas en expansión, con una amplia base de recursos minerales, con contactos permanentes y sólidos con la comunidad bancaria internacional y que, en el caso de los países recientemente independizados, sostienen buenas relaciones políticas con sus antiguas metrópolis.

Fueron los sectores públicos de los países en desarrollo, más que los privados, los que se beneficiaron en mayor medida de los créditos en euromonedas, destacando la participación de las empresas públicas extractivas, y de transformación. A finales de 1979, por ejemplo, casi el $90 \%$ de los eurocréditos canalizados al Tercer Mundo -entre 1976 y 1979 esta cifra fue de 120.000 millones de dólares- fue absorbido por los gobiernos (36\%) y los sectores públicos $(54 \%)$, y sólo una pequeña parte $(8 \%)$ fue a los sectores privados de los prestatarios ${ }^{18}$.

En países como México y Brasil -los más importantes deudores del euromercado- y en otros considerados como de industrialización reciente y acelerada (NIC's), el sector privado empezó a ganar su importancia, adicionando a la deuda externa total del país y al peso total de su servicio sobre su sociedad.

La "latinoamericanización" del euromercado -y más globalmente, su "tercermundización"- parecen sin embargo, fenómenos pertenecientes al pasado decenio. En el presente, ya se señaló, el euromercado como tal se ha encogido relativamente, y dentro de él, los préstamos a países en desarrollo, y más concretamente, a América Latina se expanden con menor rapidez que en el pasado. De suma importancia para explicar esta situación a nivel regional, resulta, justamente, la gran participación de América Latina en el euromercado durante los años setenta. Si en 1973 el monto de su deuda con ese mercado era de 3.399 millones de dólares, para 1976 esa cifra se había elevado en un $250 \%$, alcanzando un volumen de 8.499 millones de dólares, sólo para registrar, en 1979, el espectacular nivel de 25.466 millones de dólares. En 1980, se da el quiebre; ese año, América Latina recibe sólo 17.883 millones de dólares. Durante ese período, tan sólo México, Brasil y Argentina, captaron más de las dos terceras partes del total regional, y esta situación es justamente culpable, hasta cierto punto, de la "saturacion" regional en el euromercado. La enorme importancia de sólo tres países, puso sin duda nerviosa a la banca transnacional, que se sobreexpuso en ellos y observa con preocupación que su desmedida actividad.

${ }^{18}$ Loc, cil. 
puede tener consecuencias graves: externamente se corrieron riesgos excesivos; internamente se pasaron por alto controles y reglamentaciones. No es pues en balde que en la actualidad se ciernan serias dudas sobre el sistema financiero internacional, tanto por lo que hace a las posibilidades de un buen número de países para honrar sus compromisos con la banca transnacional, como por lo que toca a las posibilidades de esa misma banca para seguir proporcionando a sus deudores los recursos que necesitan para pagar esas deudas, manteniendo así un proceso de circulación de dinero bastante artificial, pero que hoy evita que el sistema colapse.

\section{III}

Puede decirse que, en términos generales, el decenio de los años ochenta se anunció y actualmente se manifiesta, preñado de dificultades para el conjunto del mundo en desarrollo y, en particular, para América Latina, la región más expuesta de esa parte del planeta, en términos de deuda externa. Si bien es cierto que los riesgos de quiebras $y$ desfalcos en esos países no se materializaron en experiencias concretas, ni tampoco se dieron las tan temidas (por la banca transnacional) renegociaciones masivas o las moratorias globales, los países en desarrollo fueron duramente golpeados por los aumentos de las tasas de interés, con los que la administración norteamericana pretendió solucionar sus problemas inflacionarios.

En 1980, la tasa de interés "prime", que es la del mercado norteamericano, representó un aumento nominal de más del 100\% respecto a los niveles de 1977 . En 1979, la tasa "liber", que es aquella cobrada en el mercado de Londres, había registrado un incremento prácticamente similar. En ambos casos, dichas tasas de interés en términos reales pasaron de ser negativas a ostentar valores oscilantes en torno al $10 \%$ anual. $Y$ si bien es cierto que en la actualidad se habla de un ligero descenso de las tasas de interés, debe aclararse que en los casos en que esto es cierto, se trata únicamente de su expresión nominal, pues en presencia de un deterioro constante de los términos de intercambio para los países en desarrollo, es un hecho que en términos reales, las tasas de interés han continuado en ascenso.

El impacto sobre los países latinoamericanos del alza en Ias tasas de interés en los países centrales, ha sido severo. En primer lugar, han visto reducidas sus opciones de política monetaria interna. Se produjo una transferencia masiva de capitales hacia Estados Unidos y en menor medida al euromercado, especialmente desde aquellos países con economías abiertas y escasas restricciones a los movimientos de capital, con resultados negativos sobre la balanza de pagos y el tipo de cambio, apreciándose el dólar y debilitándo- 
se otras monedas. En casi todos los palses debieron elevarse las tasas de interés, lo que restringió la posibilidad crediticia interna, con efectos recesivos de magnitud, al desincentivar la inversión y reducir el consumo.

En segundo lugar, y sobre esta cuestión se dieron detalles páginas atrás, las nuevas tasas han significado mayores pagos por el servicio de la deuda externa y han contribuido a poner fin a aquella creencia compartida por un buen número de países en desarrollo, y ya señalada aqui, de que sus necesidades financieras enfrentaban una oferta infinitamente elástica de recursos en condiciones aceptables. En ese sentido, vale la pena señalar aquí, por ejemplo, que los pafses en desarrollo confrontan, adicionalmente, el problema de un endurecimiento de la estructura de su deuda vía acortamiento de los plazos de amortización. Se estima que el $95 \%$ de la deuda de países no petroleros con el euromercado vencía a finales de 1982.

De una manera u otra, vía intereses o plazos, no puede negarse que el endurecimiento de las condiciones a las que se sujetan los créditos externos tiene serias repercusiones para el mundo en desarrollo en general, y también para América Latina. En primer lugar, porque hace cada vez más difícil la posibilidad de financiar niveles deseables de crecimiento económico que den lugar a un desarrollo estable y equilibrado, condenando inclusive a algunos parses a su marginación internacional o a su entrega total al capital foráneo y a intereses ajenos a su identidad nacional.

En segundo. Iugar, porque lleva a que los esfuerzos destinados a obtener recursos externos para reforzar su desarollo nacional cedan el paso de manera creciente a aquellos esfuerzos dedicados a obtener esos mismos recursos externos, pero con la casi única finalidad de poder servir una deuda que se acumula y pone en peligro la soberanía plena de los países deudores si no se paga.

No en balde se habla de la existencia de un "círculo vicioso del endeudamiento externo" de los países en clesarrollo, que hace que, a un ritmo creciente, la nueva deuda contratada se destine a servir la antigua. A manera de ejemplo, baste señalar que se estima que para finales del presente decenio, más de la mitad de la deuda nueva de los países no petroleros contraída en el mercado de euromonedas habrá de destinarse a refinanciar deudas vencidas; ésta ya es una verdad en rarios países latinoamericanos hoy.

Si bien se reconoce la importancia del hecho de que entre 1973 y 1980, y apoyados en los abundantes recursos financieros resultantes del primero y segunclo "choque petrolero", los bancos internacionales prestaron solamente a los países no petroleros, cerca de 200.000 millones de dólares, no puede ignorarse que en ese mismo período, dichos países pagaron a sus acreedores -fundamentalmente bancos internacionales- 102.800 millones de dólares por concepto de intereses, y 185.700 millones de dólares por concepto de amorti- 
zaciones, lo que una vez más arroja serias dudas sobre las corrientes netas y las "bondades del sistema"18.

Tal situación puede muy bien interpretarse como una clara señal de que el sistema financiero internacional ha entrado en un proceso de franco agotamiento y que tal vez pueden pensarse en intentar ampliar el espacio para que el mundo en desarrollo en generál y América Latina en particular, puedan negociar con éxito nuevas reglas del juego financiero. Para ello, no deben perderse de vista algunos de los cambios más importantes que en ese ámbito se están generando, con la intención de aprovechar en favor de la región y del mundo en desarrollo en general, algunas de sus manifestaciones.

En primer lugar, se ha acabado por reconocer el fenómeno de "doble cautividad" deudores-acreedores. Por primera vez los banqueros internacionales parecen haber tomado conciencia plena de que, si el sistema colapsa, ellos también tienen mucho que perder. Ya no se trata de extraer la riqueza del mundo en desarrollo a como dé lugar; sus capitales, su existencia misma se encuentra tan comprometidos en esa región del planeta, que de no facilitarle su supervivencia, los propios bancos transnacionales podrían desaparecer. Cuando se lee en informaciones oficiales norteamericanas que los nueve más importantes bancos de ese país tienen más de 220\% de su capital invertido en los países del Tercer Mundo, la vulnerabilidad del sistema bancario internacional, y la no sólo la de los países en desarrollo como se suponía en el pasado, queda puesta de manifiesto ${ }^{20}$.

En segundo lugar, el propio Fondo Monetario Internacional ha perdido, a todas luces, parte de su antigua fortaleza. Su batalla por duplicar sus recursos y la dura oposición norteamericana que hizo posible un aumento de tan sólo el $50 \%$, no es el único problema. Es un hecho que en los años setenta la institución perdió su razón original de ser; no fue capaz de mantener las reglas del acuerdo de 1944 en cuanto al papel del oro, a la libre convertibilidad o a la estabilidad monetaria, ni fue capaz de mantener con efectividad el monopolio de la creación de liquidez internacional. Los bancos transnacionales acabaron desplazándolo; ellos se convirtieron en los principales creadores de dinero a nivel mundial y en supervisores .por excelencia, si bien no siempre eficientes, del funcionamiento de las economías en desarrollo, recurriendo al Fondo Monetario Internacional más para sancionar sus propias acciones que para anticiparlas. Sin embargo, en los últimos tiempos, los peligros de in-

${ }^{19}$ Fondo Monetario Internacional, International Capital Markets (occasional paper 7). Washington, D. C., agosto 1981 y Fondo Monetario Internacional, Forld Economic Outlook (occasional paper 4), Washington, D. C., junio, 1981. sosirca, nota 12. 
solvencia y sobreexposición a los que estos bancos se enfrentan los han llevado a tratar de escudarse una vez más en el Fondo. Pero ahora la institución no tiene la fuerza de antes. Cierto, ha logrado comprometer a un número creciente de paises en desarrollo, que se han visto obligados a renegociar sus cuantiosas deudas externas y a firmar acuerdos estabilizadores, pero gran parte de la antigua fe, infundada si se quiere pero real, en la institución, se ha perdido. No sólo una cantidad creciente de analistas y polf́ticos pone en duda la efectividad de las soluciones monetaristas en un buen número de países en desarrollo y aún desarrollados, sino que los propios banqueros transnacionales buscan nuevos foros, si no de negociación, al menos de acción concertada. Tal es el caso del recientemente establecido Instituto de Finanzas Internacionales en la ciudad de Washington, cuyos origenes se remontan a 1982 en Ditchley. Inglaterra, y que será motivo de discusión en la próxima sección

En tercer lugar, las autoridades financieras internacionales y norteamericanas, conscientes de los dos hechos anteriormente anotados, intentan trabajar en algún tipo de acuerdo que permita la supervivencia del sistema, sin tener que reformarlo a profundidad. El Fondo Monetario Internacional y el Banco Mundial han empezado a recomendar a los banqueros flexibilidad; se insiste en que no pueden "abandonar" al Tercer Mundo, y que del mantenimiento de sus operaciones en esa región depende buena parte de la permanencia del sistema. Las autoridades norteamericanas han acabado por aceptar ese punto de vista, como parecen probar los casos de México y Brasil recientemente, pero mantienen su oposición al diseño de posibles reglas generales: el carácter bilateral, pragmático y casuístico de toda manifestación de política norteamericana que tenga que ver con el exterior, es defendida a ultranza.

En cuarto lugar, proliferan los grupos de estudio, las instituciones y los trabajos de todo tipo que pretenden coadyuvar a la búsqueda de soluciones, al tiempo que persiste un tono de alarma en la prensa financiera.

Por último, ese tono de alarma que parece permear todos estos ć́rculos, se ha visto alimentado no sólo por las crisis financieras de Polonia, México, Brasil, etc., sino por las quiebras recientes de algunas instituciones financieras y productivas norteamericanas y europeas, y su impacto para Estados Unidos y el resto del mundo. Tales son los casos del Penn Square Bank, del Abilene (Texas), del United American (Knoxville), de la Drysdale Securities, de Braniff International, del Banco Ambrosiano y de la AEG Telefunken, para mencionar algunos.

Todos estos acontecimientos, se insiste, podrían generar espacios importantes para reactivar la lucha por el establecimiento de nuevas reglas para el juego financiero internacional. En esa lucha, América Latina está sin duda llamada a jugar un papel fundamen- 
tal, no sólo por el peso de sus compromisos financieros actuales -recuérdese que la deuda externa latinoamericana es la más grande del. Tercer Mundo-, sino por su tradicional militancia en la lucha por reivindicaciones económicas a nivel mundial.

\section{IV}

La llamada "crisis mexicana", oficialmente reconocida en agosto de 1982, puso de manifiesto una serie de eventos cuyas repercusiones alcanzan al conjunto de la comunidad financiera internacional, y a algunos de los cuales ya se hizo referencia en estas páginas. En primer lugar, se hizo evidente que el caso mexicano no era el único en la región: las graves dificultades financieras de Brasil y Argentina muy pronto se hicieron públicas también; la crisis chilena, por un lado, y la venezolana, por el otro, adicionaron a la seriedad del panorama latinoamericano casi de inmediato; el resto del área no, está en mejor situación.

En segundo lugar, se hicieron evidentes tambien dos hechos hasta entonces difícilmente aceptados: la doble cautividad entre deudores y acreedores, así como la interdependencia de su gran vulnerabilidad. El peso de la deuda externa latinoamericana en el conjunto de la del Tercer Mundo, su alto grado de concentración en unos cuantos pafses y la importancia de Argentina, Brasil y México como deudores de la banca internacional $-\mathrm{a}$ tal punto que hoy los banqueros internacionales se refieren a ellos como "el problema MBA" 21 _ obligó a las autoridades financieras internacionales y norteamericanas a reconocer públicamente que la salvación del sistema dependía del rescate de sus partes más afectadas. Se trata, sin emibargo de una actitud que busca preservar prioritariamente los intereses de los acreedores más que los de los prestatarios, como se desprende del hecho de que las soluciones planteadas, más que habilitar a estos últimos para reconstruir una capacidad de pago más permanente, apoyada por un desarrollo económico, nacional y cada vez más autosuficiente que a su vez contribuyera a la eventual superación de la recesión mundial, busca capacitarlos para hacer frente sólo a sus compromisos de liquidez a corto plazo: el pago de los intereses sobre sus cuantiosas deudas externas.

No en balde un tercer fenómeno a anotar aquí sea, justamente, la modificación en las actitudes más tradicionales y conservadoras de esas autoridades en cuanto al otorgamiento de créditos adicionales a países con problemas. Al asumirlas los banqueros como la única vía de recuperación de sus inversiones, sólo compran tiempo, aplazando la que podría ser una especie de crisis final que supera

"Anthony Harris, "Frustrarán un repunte el déficit de Estados Unidos y la espiral de deudas". Excelsior, 24 de febrero, 1983. 
la esfera meramente financiera, para proyectarse en la productiva; al priorizarse el pago de intereses se castigan las importaciones y la industrialización del Tercer Mundo, pero también las exportaciones y las posibilidades de recuperación del mundo desarrollado, y se ignora el hecho de que la interdependencia internacional no es únicamente financiera y exige soluciones estructurales y demás largo plazo.

En cuarto lugar, y muy vinculado a lo anterior, debe destacarse la relativa recuperación del liderazgo del Fondo Monetario Internacional, menos como prestamista, pese al reciente incremento de sus recursos, y más como aval, rector, e inclusive supervisor de los severos programas de ajuste impuestos por la institución y tendientes, ya se señalaba, a preservar los intereses de los prestamistas y la supervivencia de un sistema a todas luces en crisis, y que contribuyen a negar el carácter estructural de los problemas de los prestatarios.

Finalmente, al lado de los esfuerzos de las autoridades financieras internacionales y norteamericanas para concertar ese tipo de arreglos entre deudores y acreedores, de los cuales "el paquete mexicano" -que involucró al propio Fondo, al Banco de Pagos Internacionales, a la comunidad bancaria internacional y a las autoridades norteamericanas, y ha dado lugar inclusive a la creación de un "programa especial" dentro del Banco Mundial para proteger el acervo infraestructural no sólo de México sino de otros países que como Brasil y Argentina ven peligrar todo lo que su industrialización logró hasta ahora21bis - constituye un ejemplo bastante ilustrativo, descuellan por su importancia, y hasta cierto punto por su novedad, los esfuerzos de los banqueros privados para concertar sus polfticas frente a sus deudores. El recientemente creado Instituto de Finanzas Internacionales, al que ya se hizo mención, es el ámbito en el cual, al margen de otras entidades gubernamentales, como el FMr, la OCDE, o aún el Club de París, etc., los bancos internacionales, en tanto que instituciones privadas, pretenden negociar en bloque con sus deudores, presionándolos, imponiéndoles castigos y colocándolos en mayor desventaja aún: para algunos no habrá nuevos préstamos, para otros probablemente sí, pero a costos cada vez más altos.

Un análisis más detallado de estas diferentes reacciones a las que el caso mexicano abre las puertas y de su exacerbación ante las experiencias brasileña, argentina y alguna otra, parece necesario.

Ya desde principios de la década de los setentas, México era un

Ibis Este Programa de Acción Especial del Banco Mundial, supuestamente diseñado para mantener el "momentum" del desarrollo de algunos en tiempos de crisis, no se basa en dinero nuevo. De hecho el Banco mantiene su tope fijado para 1983 y to único que hace es acelerar los volúmenes previstos, en un monto de 2.000 millones de dólares entre 1983 y 1985. 
importante deudor de la banca transnacional ${ }^{22}$, y un ejemplo claro de la adopción consciente de una estrategia de crecimiento con endeudamiento. A manera de ilustración, baste señalar que la deuda externa del gobierno mexicano pasa de cerca de $\$ .000$ millones de dólares a finales de 1970 -cuando ya era clara su concepción y conceptualización como "mecanismo de ajuste" de los desequilibrios internos ( $\mathrm{I}-\mathrm{S})$ y externos $(\mathrm{X}-\mathrm{M})$, menos inflacionario y menos atentatorio de los intereses del gran capital, que otras medidas y reformas de carácter estructural - a más de 70.000 millones de dólares a fimales de 1982. Si a esta cifra se añade la deuda externa del sector privado, el volumen total se acerca a los 85.000 millones de dólares, de los cuales por lo menos 60.000 millones se encontraban contratados con la banca internacional. Por si este hecho no fuera más que suficiente para alarmar a los banqueros, la situación se agrava, desde su punto de vista, sobre todo, al reconocer que la mitad de la deuda mexicana habrá vencido para finales de $1983^{23}$. De estas enormes dificultades a las que la economía mexicana y los banqueros internacionales se enfrentan, son culpables tanto los agentes nacionales endeudados (el sector público y el privado), como los propios prestamistas.

Después de la crisis económica de 1976, con sus problemas de: menor crecimiento, devaluación, endeudamiento externo y pérdida de confianza en 'el Estado, México vuelve a adquirir importancia a los ojos de los banqueros internacionales, llegando inclusive a convertirse en uno de sus más importantes clientes, como consecuencìa de los llamados "descubrimientos petroleros" de 1977.

Provistos de cuantiosos recursos financieros, los banqueros disipaban, en el caso de México, todas las posibles dudas que sus préstamos enfrentaban en otros países del Tercer Mundo en momentos en que los precios del petróleo y las tasas de interés ascendían. La riqueza potencial del país alentaba a propios y a extraños. Las entidades públicas y privadas se endeudaban en exceso y de manera inclusive descuidada, en tanto que sus acreedores se disputaban el acceso al mercado mexicano, con la consecuencia, ya señalada, de una expansión acelerada de la deuda externa total y una acentuación de sus tendencias: más del $90 \%$ de las contrataciones era de origen privado, contribuyendo así a la idea sostenida por las agen-

\footnotetext{
-Tan sólo en el mercado de euromonedas, la deuda mexicana pasó a representar el $5,7 \%$ de todos los eurocréditos canalizados a todos los países del mundo, al $11,0 \%$ y'a en 1975 . Ese porcentaje se mantuvo relativamente elevado el resto de la década, inclusive de 1977 a 1979 México fue el primer país del euromercado. A partir del presente decenio, esa sịtuación se ha modificado, y México ha vuelto a los niveles de 1973 , tanto porque el mercado se ha reducido, relativamente, y la demanda de algunos países industrializados ha aumentado, como porque la enorme deuda mexicana desalienta a los banqueros.

Michael Moffit, "Global Banking Goes for Broke". The Progressive. Febrero, 1983, pp. 20-24.
} 
cias multilaterales de financiamiento en el sentido de que México se había "graduado" ya y había dejado de pertenecer al grupo de países subdesarrollados; más del $75 \%$ de la deuda externa del país la vinculaba, como ya se señaló, a la banca privada transnacional, sujetando los destinos nacionales a la inestabilidad y el voluntarismo bancario; los bancos norteamericanos recuperan parte de su tradicional dominio en el ámbito de la deuda externa mexicana, no sólo en términos del sector privado, donde en realidad este dominio se mantuvo siempre como un hecho indiscutible, sino en términos del sector público, y por ende, del país como un todo; a tal punto que si hoy México concentra con la banca norteamericana un tercio de su deuda total con la banca internacional, esta situación tiene repercusiones nacionales serias, pues testimonia el grado de dependencia en que las actividades económicas mexicanas, incluidas las financieras, se relacionan con el destino económico estadounidense.

A medida que los precios internacionales del petróleo ascendían, México se colocaba como el país con la tasa más alta de crecimiento de la región, y sus cuantiosas reservas energéticas eran vistas como un seguro valioso frente a cualquier problema. No en balde en 1981, México sobrepasó a Brasil, en tanto que el principal deudor del Tercer Mundo, consiguiendo volúmenes crecientes de recursos externos en condiciones ventajosas, pese a la tendencia al alza de las tasas de interés, debido al pago de diferenciales definitivamente bajos: $0,5 \%$ sobre la tasa de interés bancario de Londres (LIBOR).

El punto de inflexión, sin embargo, en esta luna de miel con los banqueros, llegó a mediados de 1981. Los precios y ventas del petróleo mexicano, y por tanto su ingreso esperado, disminuyeron de manera significativa, al tiempo que se registraba el descenso también de otros productos mexicanos de exportación. El gobierno se vio enfrentado a la necesidad de suplir ese ingreso en divisas con deuda externa, aún si de corto plazo: durante el segundo semestre de 1981, se contaron 15.000 millones de dólares, de los cuales prácticamente 10.000 millones fueron de corto plazo. En 1982 la economía mexicana debió enfrentarse a dificultades todavía más serias. En primer lugar, el tipo de cambio (cuya nueva paridad después de la devaluación de 1976 ya se había agotado) se desplomó, pasando de los 27 pesos por dólar que prevalecía a principios de esé año, a casi 50 pesos a mediados del mismo, sólo para fluctuar entre 100 y 200 pesos después de los controles de cambio de septiembre, y estabilizarse, relativamente, en torno a los 150 pesos y al lado de otros dos tipos de cambio: el especial, para importaciones preferenciales, en torno a 100 pesos, pero a la baja; y el controla- 
do, para pagar la deuda externa, en torno a 90 pesos y también a la baja ${ }^{23 \text { bis. }}$

En segundo lugar, la inflación se desbordó, pasando de niveles de 30 y $35 \%$ al $100 \%$ a finales de 1982 .

En tercer lugar, el crecimiento se vio brutalmente frenado. La tasa histórica se había mantenido alta, en promelio, durante un largo número de años. Hablar del $6 \%$ de crecimiento del pIB al año era bastante común, a pesar de algunos descalabros como en 1971, 6 1976. El gobiezno de Lopez Portillo, sin embargo, y a pesar de declaraciones oficiales en contra, optó por una meta de crecimiento superior: entre 8 y $9 \%$ anual, no sólo demasiado alta tal vez, sino a ser alcanzada demasiado pronto. La meta se logró a toda costa: con sobreendeudamiento externo, sobrediversificación y sobrecalentamiento. Esta situación, si bien creó un nivel de empleo sin precedentes, resultó insostenible a mediano plazo y el resultado fue el ajuste: desde febrero de 1982 se decretó una serie de restricciones en el sector público, con impacto sin duda en el sector privado, que unidas a otras situaciones como las dificultades para conseguir todo el crédito extemo necesario - pilar fundamental en esta estrategia de crecimiento acelerado y hasta cierto punto desordenado- llevaron a una tasa de crecimiento de la economía nacional cercana al $0 \%$ a finales del año.

En cuarto lugar, el mantenimiento de una paridad artificial del peso con el dólar y el enorme diferencial en los niveles de inflación mexicana y norteamericana, estimularon una fuga de capitales, conservadoramente calculada en 22.000 millones de dólares, que saqueó, las reservas internacionales del país y forzó la contratación de más deuda externa.

Por último, el peso de los intereses y del principal de la cuantiosa deuda pública externa, reflejo del alza de las tasas de interés a nivel internacional y del acortamiento de los plazos, llevó a la moratoria sobre pagos de principal de agosto, ncgociada por el gobierno mexicano y sus acreedores privados, que le permitió a México un respiro de tres meses. Al final de este período, vale la pena señalar, se solicitó una extensión de cuatro meses, que acabó en un acuerdo cuyas condiciones especifican que los práctıcamente 20.000 millones de dólares adeudados por el gobierno mexicano por concepto de principal se convierten en un crédito a 8 años de plazo -1983-1990 - con un período de gracia de 4 años; los pagos empezarán, así, a partir de 1987.

Lia reacción de los banqueros internacionales a la moratoria de agosto, no se hizo esperar. Los nuevos préstamos a América Latina, que habian disminuido dramáticamente durante la guerra de las 1983.

obisEste tipo de cambio llamado "mexdólar", desapareció el 15 de marzo de 
Malvinas, Ilegaron a una situación de franco estancamiento ${ }^{24}$. Los bancos: pequeños se salieron del mercadö, y los grandes bancos se quedaron solos para hacer frente a las crecientes demandas de recursos planteadas por los pafses latinoamericanos a fin de poder servir sus antiguas deudas. Estas dificultades y los crecientes temores de-una moratoria conjunta, o al menos la unión de Argentina; Brasil y México, alentados por la progresista medida adoptada el primero de septiembre por el gobierno de este último país de nacionalizar la banca privada, a la que se responsabilizaba de todos los problemas internos ( $y$ el miedo de que, por asociación se culpara a la banca internacional de todos los problemas del sector ex. terno mexicano), permearon la trigesimaséptima reunión conjunta del Banco Mundial y el Fondo Monetario Internacional de septiembre de 1982.

Si el "caso mexicano" se convirtió en el centro de atención, los de Argentina y Brasil estaban tan sólo a un paso de distancia. La discusión por lo tanto se enfocó, ya se señalaba, en la salvación del sistema vía el a poyo a estos países. Se generó entonces un consenso que, se insiste, tenía en mente más a los acreedores que a los deudores: se proporcionaría dinero para apoyar al sistema financiero sólo si los países fuertemente endeudados aceptaban someterse a un prolongado período de restricción económica. No en balde, un segundo componente de esta "solución" fue la batalla, librada entonces y sólo ganada muy recientemente, de incrementar los recursos del FMI, que al fin de cuentas es la institución diseñada por el mundo industrializado de Occidente para supervisar los programas de ajuste exigidos al mundo en desarrollo. Se solicitó entonces la duplicación de los recursos de la institución, acabó acordándose un aumento del $50 \%$, que por cierto puede no lograrse debido a la tradicional actitud negativa del Congreso norteamericano frente a lo que califica como "asistencial".

Concretamente, en su discurso inaugural, el Director del FMI, Jacques de Larosière, hizo un llamado a los bancos comerciales, solicitándoles no reducir sus préstamos a los países en desarrollo. "Cuando problemas de deuda, como los que presenciamos en la actualidad, surgen -señaló-, debe darse una estrecha colaboración entre todas las partes interesadas" ${ }^{\prime 25}$.

El discurso del señor De Lorosière fue de hecho interpretado como una llamada de atención a los banqueros comerciales por sus politicas de préstamo, en extremo liberales y hasta descuidadas. "En muchas ocasiones -dijo- los cambios en la dirección del finan-

"Según el Banco de Pagos Internacionales, en los primeros nueve meses de 1982, los préstamos al área se redujeron en 4.200 millones de dólares, mientras que en igual periodo de 1981, esos patses pudieron obtener 4.000 millones de dólares nuevos. Excélsior; 19 de enero, 1983.

NNew York Times, septiembre 7, 1982. 
ciamiento bancario han sido abruptos y muy grandes en relación a la cuenta corriente de las balanzas de pagos de los países involucrados; han creado problemas tanto de manejo interno de las economías como de financiamiento para balanza de pagos en los pafses prestatarios"26.

En clara referencia al caso mexicano y su impacto sobre el resto de la región, De Larosière instó a los prestamistas comerciales "a juzgar a cada deudor sobre la base de sus propios méritos, y a no permitir que el surgimiento de problemas de financiamiento de la deuda en un país enturbiara su juicio sobre la capacidad de crédito de países vecinos"27. -

A partir de ese momento, un buen número de países de América Latina, empezando por los grandes, ha intentado resolver sus problemas de deuda, firmando, como primer paso, un acuerdo de estabilización con el FMI, considerado por los banqueros privados como garantía de su disposición a dar prioridad al cumplimiento de sus compromisos de deuda. A partir de ese momento, también, De Lorosière ha insistido en su posición: para evitar que el sistema quiebre, para evitar el colapso de los prestamistas, los prestatarios dispuestos a ajustar sus economías y repensar sus políticas económicas según la ortodoxia monetarista, recibiran los recursos necesarios para honrar sus compromisos externos.

México recibió del FMr la promesa de obtener 3.900 millones de dólares, a lo largo de los tres años del acuerdo. Adicionalmente, la firma del convenio le permitió acceder a los 1.350 millones de dólares prometidos por el Banco de Pagos Internacionales; a los 2.000 millones de dólares ofrecidos por el gobierno norteamericano a cuenta de futuras ventas de petróleo, así como a otros créditos de esa nación: fundamentalmente para la adquisición de granos y productos alimenticios. Igualmente, la sujeción a la disciplina del Fondo permitió a México negociar un crédito "jumbo" con más de 1.400 bancos occidentales y japoneses, firmado el 3 de marzo de 1983 (tras el vencimiento de enormes dificultades, fundamentalmente relacionadas con la salida del acuerdo inicial de un buen número de bancos pequeños y la necesidad de reemplazarlos con atros, ya saturados), por un monto de 5.000 millones de dólares, sujeto a una tasa de interés que implica el $2,25 \%$ sobre la $x$ LBOR y por un período de seis años.

Brasil, por su parte, recibió del Fondo la promesa de recursos aún mayores: 5.200 millones de dólares sujetos, por supuesto, a la firma y cumplimiento de un programa estabilizador similar al acordado con México. Argentina recibirá 2.200 millones de dólares. Otros países como Perú (700 millones de dólares) y Chile $(600 \mathrm{mi}$ -

${ }^{s a}$ Idem.

${ }^{27}$ Idem. 
llones de dólares) ${ }^{28}$, están en situción similar, y Venezuela empieza a considerar su acceso al Fondo, después de su enorme devaluación y del establecimiento de controles de cambio, buscando evitar lo que ha constituido uno de sus problemas más serios de los últimos tiempos: una descomunal fuga de capitales que se calcula en más de 50.000 millones de dólares.

Al lado de las exigencias de ajuste planteadas por el FMI, que de ninguna manera son nuevas y cuya capacidad para ayudar a resolver los problemas estructurales de América Latina, es frecuentemente cuestionada, está el asunto de otro procedimiento, reiteradamente utilizando también e igualmente fallido. la renegociación de las deudas. Desde 1956, año de la primera renegociación de la deuda argentina en el Club de París, hasta 1982, se han llevado a cabo 22 procesos de renegociación en la región, los :cuales han constituido, inclusive, una práctica recurrente en varios países (Argentina, por ejemplo, ha tenido $4_{\text {; }}$ la más reciente justamente en 1982), lo que arroja dudas aún más serias sobre su aporte a la problemática regional ${ }^{29}$.

Pero, obviamente, esta no es una preocupación de fondo de las autoridades financieras internacionales, cegadas por las perspectivas de corto plazo y concentradas en problemas de flujo de caja. En ese sentido, la posición de A. W. Clausen, Presidente del Banco Mundial, no difiere prácticamente en nada de la sostenida por el Director del FMr.

${ }^{25}$ Newsweek, enero $31,1983$.

$=$ Renegociaciones latinoamericanas desde 1956. (US\$n).

\begin{tabular}{llllll}
\hline Año & Pais & Cantidad & Año & \multicolumn{1}{c}{ Pais } & Cantidad \\
1956 & Argentina & 500 & 1978 & Perú & 1.212 \\
1961 & Brasil & 300 & 1980 & Nicaragua & 562 \\
1962 & Argentina & 270 & 1981 & Bolivia & 460 \\
1964 & Brasil & 270 & & Nicaragua & 180 \\
1965 & Argentina & 274 & & Jamaica & 109 \\
& Chile & 90 & $1982 *$ & Argentina & 5.000 \\
1968 & Perú & 120 & & Costa Rica & 2.600 \\
1969 & Perú & 100 & & Cuba & 800 \\
1972 & Chile & 258 & & Honduras & 220 \\
1974 & Chile & 460 & & Néxico & 40.000 \\
1975 & Chile & 230 & & Ecuador & 1.000 \\
& & - & & & \\
\hline
\end{tabular}

FUENTE: Informe Latinoamericano $1 \mathrm{~L}-82-05,15$ de octubre de 1982.

* En proceso; montos a renegociar aún no precisados. 
Clausen ha apelado, también, en repetidas ocasiones, a los paises industrializados y a los bancos privados, "para que mantengan, a pesar de la preocupación por el alto endeudamiento externo, la asistencia financiera a los países del Tercer Mundo". Concretamente, Clausen ha solicitado a la banca privada que "continúe, si bien con precaución, su importante desempeño en la financiación a pajses con dificultades de pago"30.

El presidente del Banco Mundial ha manifestado su convencimiento de que la "paciencia y buena voluntad" de los banqueros será premiada. En un artículo que le publicó el New York Times, Clausen escribió: "Es verdad que algunos bancos han cometido errores, como tambien lo han hecho algunas naciones en desarroIlo, pero el remedio consiste en dejar de cometer errores y no en ponerle un alto a los préstamos"31.

En su opinión, el primer paso hacia la solución consiste en el reconocimiento de que las deudas no constituyen el principal problema sino que son tan sólo un síntoma. "El problema verdaclero es la falta de crecimiento. A menos que las inversiones rentables se mantengan, no se generará el suficiente crecimiento para servir las deudas. Las deudas pueden ser manejadas, pero sólo si el crecimiento se sostiene y se evita el proteccionismo" 32 .

En su opinión, las deudas son una especie de "mal necesario", siempre existieron, y si ahora se hacen pesadas es por la recesión mundial y su impacto sobre los países en desarrollo. Los altos precios del petróleo, combinados con altas tasas de interés, menores precios de otras materias primas diferentes al petróleo, y demanda reducida en el mundo industrializado por los productos del mundo en desarrollo, resultaron una combinación fatal. La deuda externa de los países en desarrollo se desbordó y los bancos internacionales empezaron a extremar sus precauciones. Muchos países estuvieron a punto de quebrar: La contracción se impuso como regla, y la pregunta no se planteó entonces, si bien Glausen se la hace: ¿qué impacto tiene la contracción en el Tercer Mundo sobre las posibilidades de recuperación del mundo desarrollado? "Las exportaciones de bienes y servicios - aclara- contribuyeron más de dos veces a nuestro producto en 1979 que en 1970. Cerca de dos quintas partes de nuestras exportaciones van a países en desarrollo. Si el comercio mundial se contrae, nuestro déficit comercial crece y más empleos se pierden" 3 .

No en balde "La tarea de ayudar a las naciones en desarrollo a sostener su crecimiento no puede sex lograda por los bancos comer-

sorno más Uno, 24 de septiembre, 1982.

"The New York Times, 22 de febrero, 1983.

saldem.

Idem. 
ciales solos. Ellos, junto con las instituciones internacionales de préstamo, deben unirse a los gobiernos para mantener el crecimiento, Iuchar contra el proteccionismo y ayudar a las naciones más pobres a desarrollar su enorme contribución potencial a la economfa mundial. [En otras palabras]... Las naciones en desarrollo mismas deben hacer grandes esfuerzos para ajustarse y reformarse. Pero las naciones desarrolladas y las organizaciones internacionales deben ayudarlas, resistiendo el proteccionismo y asegurando una expansión de las corrientes de capital, incluidos niveles realistas de asistencia. De otra forma, sufriremos todos"34. En este esfuerzo que incluye a toda la comunidad internacional, el presidente del Banco Mundial, asigna a Estados Unidos el papel de líder ${ }^{35}$.

Clausen no es, sin embargo, el único personaje que señala el papel que las importaciones del mundo en desarrollo pueden desempeñar en la superación de la recesión de los palses desarrollados y en la necesidad de que dichas importaciones sean facilitadas por la comunidad internacional, incluidos los bances extranjeros. Algunos cálculos recientes señalan que la presión de las deudas y los acreedores ( $y$ sin duda también las de los programas de ajuste según la ortodoxia monetarista del Fondo), ha hecho peligxar parte de los 308.000 millones de dólares que representan las exportaciones de los países industrializados hacia las naciones en desarrollo y lo que éstas significan en términos de empleo: cinco de cada cien en términos globales y uno de cada seis en Estados Unidos ${ }^{36}$.

Por otro lado, la línea oficial norteamericana, expresada por Paul Volcker, presidente del Sistema de la Reserva Federal, es bastante acorde con las expresiones de los responsables de las instituciones financieras internacionales a las que se ha hecho referencia. Concretamente ha señalaclo: "Los bancos prestamistas, que trabajan juntos en forma efectiva para satisfacer una necesidad transitoria, evidentemente justificada, deben poder ofrecer el margen necesario de financiamiento mientras reducen la proporción de los préstamos pendientes relativos a su capital o activos" 37 . Indicó su convicción de que el reajuste de algunos préstamos y el abastecimiento de nuevos fondos, de acuerdo a programas aceptados por el Fondo Monetario Internacional, será en algunos casos la forma más efectiva y prudente de mejorar la solvencia de los países prestatarios $y$, por lo tanto, de proteger los propios intereses de los bancos ${ }^{38}$.

El Secretario del Tesoro de Estados Unidos, Donald T. Regan, en una larga presentación ante el Comité de Banca, Finanzas y Asuntos Urbanos, de la Cámara de Diputados, con fecha 21 de di-

sIdem.

"The Christian Science Monitor, febrero 10, 1983.

saxcélsior, 11 de febrero, 1983.

Excélsior, 30 de diciembre, 1982.

"Idem. 
ciembre de 1982, coincidió ampliamente con el argumento anterior. Después de describir las razones y la enorme dificultad de los problemas económicos $y$ sociales que el mundo en general y el subdesarrollado en particular, enfrenta, enfoca su atención en la visión que de la situación tienen los bancos internacionales.

"Los principales bancos internacionales tienden a percibir el problema de la deuda de los países en desarrollo como uno de liquidez más que de solvencia. En su opinión, esto es el resultado de polfticas domésticas equivocadas y de debilidad de la economía mundial [de ahí que] medidas internas correctivas y recuperación de la economía internacional [constituyan la clave que] restaurará la capacidad de crédito de esos países en el largo plazo. Las principales dudas emanan, entonces, del tiempo que tomará el restablecimiento de la confianza $y$ de la capacidad de los nuevos créditos provenientes de la comunidad bancaria para mantener el apoyo en tanto que se realiza el ajuste. La esencia del problema es, así, asegurar que se establezcan las condiciones adecuadas a fin de reconciliar la prudencia necesaria al prestar con los requisitos de financiamiento continuo mientras se da el ajuste" 39 .

En opinión de Regan, esto es fundamental para asegurar la permanencia del sistema financiero internacional y salvaguardar al sistema bancario estadounidense, que desempeña en él un papel fundamental.

"Los bancos norteamericanos representan cerca de una tercera parte de todos los préstamos bancarios internacionales canalizados a prestatarios finales: 349.000 millones de dólares a mediados de 1982, de los cuales una cuarta parte va a América Latina" 40.

Si Estados Unidos y otros gobiernos extranjeros se "lavaran las manos" frente a los problemas de deuda del Tercer Mundo y no les canalizaran los nuevos préstamos que necesitan para hacer frente a sus compromisos y compras externas, sería, en opinión de Regan, catastrófico, dados los obvios vínculos entre comercio y banca. Sufrirían en primer lugar, los países industrializados, pues sus exportaciones podrían verse reducidas entre 35.000 y 45.000 millones de dólares, lo que podría representar una caída total de su PIB de hasta un $1 \%$ y poner en serio entredicho sus posibilidades de recuperación. Para Estados Unidos, concretamente, los resultados serían bastante similares: una caída de $1 \%$ en el PIB y la pérdida de cerca de 12.000 millones de dólares en ingresos esperados, provenientes de exportaciones al Tercer Mundo.

Además, si los países en desarrollo no reciben nuevos préstamos; no sólo no serán capaces de comprar a los países industrializados,

"Departamento del Tesoro de Estados Unidos, Treasury News. Washington, D. C., diciembre 22, 1982.

ridern. 
continúa Regan, sino que tampoco podrán pagarles a los mismos banqueros que tal vez preferirían salirse ahora, y esto tendría serias repercusiones también: incapacitados para recuperar sus recursos, estos bancos no podrían, ya no sólo prestar internacionalmente, sino tampoco domésticamente, con el consecuente daño a la vida industrial y a la de los ciudadanos privados de los páses industrializados.

"La respuesta a la pregunta sobre por qué Estados Unidos debe participar en los esfuerzos para administrar y resolver los actuales problemas financieros internacionales es, entonces, que nuestros esfuerzos están en función, principalmente, de la defensa del norteamericano medio y sus propios intereses económicos. El propósito es proteger su empleo y su ingreso. Si Estados Unidos ha de prosperar, si el desempleo ha de ser reducido y si nuevos empleos deben ser creados; si la meta es fortalecer las compañías por las que trabajamos y en las cuales la inversión de nuestros fondos de pensiones y compañfas de seguros debe ser mantenida, es de vital importancia que nuestros grandes y crecientes clientes en el extranjero se mantengan saludables y se les ayude a ajustarse y recuperarse en tiempos de dificultades económicas" 41.

En su opinión, la estrategia norteamericana para lidiar con los actuales problemas del sistema financiero internacional, debería contener cinco elementos clave. En primer lugar, "el pilar de cualquier esfuerzo de larga duración para remediar los problemas de deuda de los países menos desarrollados debe ser la realización de esfuerzos domésticos de ajuste, ordenados pero efectivos, por parte de cada uno de los países interesados" 42 .

En segundo lugar, la garantfa de que se proporcionará financiamiento oficial, sobre bases transitorias, siempre que sea necesario, para permitir que ese ajuste ordenado se lleve a cabo. El papel del FMI es visto, en ese contexto, como esencial, pero el financiamiento oficial es presentado como necesario pero insuficiente.

De ahí que, en tercer lugar se exalte el papel que deberán desempeñar los bancos comerciales: no debe permitírseles la retirada. "El cese de la actividad bancaria comercial no conviene ni a los propios bancos prestamistas... Todas las instituciones bancarias comerciales - grandes y pequeñas- que han tomado parte en los préstamos internacionales que permitieron a los pafses en desarrollo prestatarios, incurrir en deudas, algunas de las cuales proporcionan divisas, otras no, deben estar conscientes de los peligros que implicaría cualquier intento de reducir su actividad en esos países en momentos en que los procesos de ajuste se están dando" 43 .

En cuarto lugar, está la voluntad y la capacidad oficial para ac-

"Idem.

irdem.

Idem. 
tuar en emergencias potenciales. Los bancos centrales, las autoridades norteamericanas, el Banco de Pagos Internacionales, recientemente demostraron en opinión de Regan, la validez de este cuarto elemento.

En quinto lugar, es fundamental contar con un conjunto de políticas económicas en los principales países industrializados capaces de producir crecimiento económico y contrabalancear los riesgos de un proteccionismo egoísta.

Ahora bien, la insistencia que las autoridades financieras norteamericanas han puesto sobre la actuación internacional de la banca comercial en un país supuestamente "friedmaniano", no se ha dado sin consecuencia.

Ante la firmeza de declaraciones y exigencias de este tipo, los banqueros protestaron. "Por primera vez en nuestra historia como banqueros independientes nos han robado nuestra libertad de acción al adoptar la decisión sobre si debemos conceder un préstamo o no. Nos han dicho que si no otorgamos un préstamos, nuestra posición en el mercado podrá verse perjudicada. Me parece que esta es una interferencia fundamental con la independencia de un banco", señaló S. M. Yassukovich, director administrativo de un pequeño banco del euromercado, el European Banking Company, en referencia al paquete mexicano de rescate propuesto por el Fondo ${ }^{44}$.

La posición de Yassukovich, sin embargo, refleja de manera fiel la de los bancos más pequeños del sistema -aquellos con activos menores de 5.000 millones de dólares-no así las de los bancos más grandes. Los pequeños bancos, que inclusive llegaron tarde al mercado y muchas veces sin la experiencia ni el personal adecuado para competir con los grandes bancos, hoy parecen compartir la firme creencia de que se equirocaron en sus percepciones del riesgo que corrían, y muchos de ellos se aprestan a retirarse del mercado. Los que se ven obligados, por el Fondo o por su propio involucramiento, se quedan con la esperanza de que la recuperación de los deudores permitirá la recuperación de los acreedores, pero han manifestado la necesidad de mejorar sustancialmente el flujo de información. Así surgen los esfuerzos por conformar la que aquí se ha llamado, "una trilateral de banqueros" acreedores del Tercer Mundo.

La idea de crear una instancia de coordinación integrada exclusivamente por los grandes bancos acreedores del mundo en desarroIlo - recientemente calificada por The Banker como un intento de formar un FM comercial-45 constituye, quizás, la más novedosa y significativa reacción de los banqueros internacionales a la que, sin duda, perciben como una injerencia de sus gobiernos en sus asuntos; es decir: a la insistencia de las autoridades financieras internacionales y de sus respectivos países de que mantengan su nivel de

Excelsior, 30 de diciembre, 1982.

"The Banker, diciembre, 1982, pp. 68-64. 
actividad en el Tercer Mundo, a fin de evitar el colapso del sistema. En otras palabras, es un hecho que los banqueros pretenden asumir, mediante esa instancia de coordinación, el control de los problemas de deuda de los países en desarrollo y sus soluciones, dado que, aparentemente, la comunidad financiera internacional los ha señalado como "culpables" (junto con las políticas equivocadas del mundo endeudado) y como responsables del costo del ajuste (y por lo tanto destinados a absorberlo) para el mundo industrializado.

Los antecedentes propiamente dichos de esta instancia coordinadora pueden encontrarse en mayo de 1982, cuando 31 de los principales bancos comerciales de Occidente y Japón se reunieron en un Iugar llamado Ditchley Park, cerca de Oxford, Inglaterra. El logro principal de la reunión fue el acuerdo entre los asistentes, de intercambiar mayor información acerca de sus créditos al exterior. Debe señalarse que si bien es cierto que en el momento de llevarse a cabo ese encuentro, se percibían las dificultades reales y potenciales del sistema financiero internacional, las crisis de deuda de finales de 1982 y principios de 1983 estaban todavía lejanas. De ahi que lo iniciado en Ditchley Park se percibiera entonces como una de las varias reuniones de contacto e intercambio de información entre banqueros, sin una idea muy clara, todavía, de cómo acabaría por consolidarse este esfuerzo. Los acontecimientos del segundo semestre de 1982 mucho tuvieron que ver con la orientación futura de estas reuniones y su resultado final.

Cuando en octubre de 1982 el llamado Grupo Ditchley, que se reúne por segunda vez, en esta ocasión en Nueva York, la magnitud de la crisis financiera internacional y del peso que en ella tienen algunos casos concretos (México, Brasil y Argentina, por ejemplo), habia quedado de manifiesto en Toronto, durante la reunión conjunta Banco Mundial-FMI. Lo que de alguna manera las autoridades financieras internacionales $y$ norteamericanas esperaban de los bancos era también evidente, y lo que quedaba por determinar era el grado y las condiciones de aceptación por parte de los banqueros de esa tarea de "rescate" que aparentemente se les imponía.

Las recientes advertencias de los bancos centrales de los países industrializados, de las instituciones multilaterales, de los reguladores bancarios y hasta de algunos bancos comerciales, en el sentido de que una reducción masiva de los préstamos bancarios a los países en desarrollo constituía una seria amenaza para el conjunto de la comunidad internacional y podía propiciar una crisis global de repercusiones gravísimas, llevó a que, en un primer momento, el Grupo Ditchley tuviera como preocupación central transmitir a la opinión pública mundial su supuesta confianza acerca de sus actividades de préstamo en el Tercer Mundo. Ya al interior del Grupo, la reunión enfocó su atención en la búsqueda de mecanismos y proce- 
dimientos para evitar que en el futuro los banqueros tuvieran que confrontar situaciones parecidas. Surgió entonces la idea de crear un Instituto de Finanzas Internacionales, que más que enfrentar la crisis con un enfoque de corto plazo, según declaraciones de uno de los miembros más importantes del Grupo -Bill Odgen, vicepresidente del Ghase Manhattan Bank- reflejara "la reconocida necesidad de un enfoque de largo plazo para facilitar el intercambio de información entre los bancos comerciales y los países deudores"46.

En principio, la membresía de esa institución estaría abierta a todos los banqueros comerciales, los cuales recibirán informes analíticos sobre la situación financiera de los países deudores, sus planes y políticas económicas y sus compromisos en divisas, existentes o propuestos. La idea detrás de este intercambio de información es capacitar a los bancos para llevar a cabo mejores evaluaciones sobre el riesgo país y facilitarles la adopción de decisiones más adecuadas. Se supone que el Instituto podría llegar inclusive a proporcionar a los países deudores un foro al que podrán acudir a plantear a los acreedores sus necesidades financieras ${ }^{47}$.

La comparación del Instituto, cuya creación se acepta en octubre en Nueva York, con una especie de FMr. comercial, está basada en el hecho de que en repetidas ocasiones se insistió, durante la reunión, en que sería conveniente que de tiempo en tiempo la institución enviara a los países en desarrollo "misiones" de banqueros, para discutir sus necesidades financieras y preparar los informes para los miembros 48 .

Finalmente, a principios del presente año, el Grupo Ditchley se reunió por tercera vez, ahora en la ciudad de Washington, y con fecha 11 de enero estableció el Instituto de Finanzas Internacionales. contando con la representación de 35 bancos comerciales en nueve países: Alemania Federal, Brasil, Canadá, Estados Unidos, Francia, Inglaterra, Italia, Japón y Suiza.

De acuerido a su estatuto, "la nueva institución está diseñada para promover un mejor entendimiento de las transacciones internacionales de préstamo, al mejorar la disponibilidad y la calidad de la información financiera y económica de los principales países deudores. Con este objeto, la organización colaborará con las naciones prestatarias en la recolección y diseminación de la información pertinente a la situación financiera de estos países, sus planes de desarrollo, sus políticas económicas, así como sus compromisos reales y potenciales denominados en monedas extranjeras. Esta información ayudará a los miembros del Instituto a establecer sus situaciones crediticias ante prestatarios individuales, al tiempo que

serdem.

${ }^{\star T}$ Fondo Monetario Internacional, IMF Survey. Washington, D. G., noviembre 15, 1982, p. 366.

${ }^{4}$ Tre Banker, op. cit. 
puede proporcionar a estos últimos un foro donde presenteń, si así lo desean, sus planes y proyecciones económicas".

Se trata asi de una supervisión a fondo, sin los posibles filtros a los que obligan, si no el pudor, al menos cierto pluralismo en las organizaciones intergubernamentales.

Ante la creciente concertación de los acreedores en instancias que dejan prácticamente de lado la acción oficial, y ante el hecho evidente de que cuando esta acción se manifiesta, bilateral o multilateralmente, busca salvaguardar los intereses de los prestamistas, los prestatarios tendrían que reaccionar igualmente de manera concertada y tener en mente, como prioridad número uno, sus intereses.

Resulta evidente que hasta ahora, por lo menos a nivel latinoamericano, los países deudores han favorecido el tratamiento bilateral de sus problemas internacionales, convencidos de que de esta manera pueden expandir su espacio negociador. La idea de capitalizar la doble cautividad acreedores-deudores a la que se ha aludido en estas páginas, no sólo no se ha planteado en ningrín caso individual, sino que cualquier instancia de negociación conjunta es violentamente rechazada sin previo análisis.

El hecho de que en Brasil y México, los nueve más importantes bancos norteamericanos tengan comprometido más del $80 \%$ de su capital, asusta a los banqueros, pero no mejora la autopercepción de los países deudores en cuanto a su capacidad negociadora conjunta.

Los patses latinoamericanos más endeudados, debe decirse, han frustrado de alguna manera, las más negativas expectativas de los banqueros. Mientras éstos se preparaban para defenderse frente a toda clase de acciones que ellos consideraban posibles provenientes de los deudores, incluidas por cierto la concertación de esfuerzos y hasta la moratoria conjunta, México, por su lado, Brasil por el suyo, y lo mismo puede decirse del resto, dedicaban sus mejores esfuerzos a demostrarle a sus acreedores, que sus juicios sobre su capacidad de pago no habían sido equivocados, y a conseguir nuevos préstamos para servir los antiguos, aún a costa de prometer ajustes y sacrificar la planta industrial, el empleo y hasta la paz social.

Resulta pues, evidente, la necesidad de sugerir que al lado de los esfuerzos individuales de los paises latinoamericanos por resolver sus problemas financieros internacionales, se plantee, con seriedad, Ia posibilidad de superar la gran dirersidad de condiciones que separa a los países de la región, votando a favor del rescate de lo que debe ser la meta común: garantizar las condiciones de un desarroIlo económico permanente y autososteniclo. En ese sentido, la con- 
certación ofrece muchas más respuestas que o el trato bilateral o la confrontación individual de los acreedores, como sucede en París, y puede seguir sucediendo en Washington.

Tal vez el mejor camino para superar los posibles temores de los páses latinoamericanos ante la concertación, y partiendo del supuesto de que existen interés y voluntad politica, sea ir planteando etapas. En ese sentido, el primer paso parecería ser el del intercambio de información. Resulta indispensable el establecimiento de un banco de datos sobre proveedores de fondos, condiciones do. los préstamos, etc., que facilite a los prestatarios la adopción de decisiones nacionales sobre dónde acudir y cuándo salir al mercado, o qué "spreads" aceptar, o hasta dónde es posible presionar para ampliar los lazos de los préstamos, por ejemplo.

Un segundo paso podría ser, generalizar las posibilidades de asistencia técnica. No cabe duda que países como Brasil y México, que cuentan con un equipo de hábiles negociadores, están en posibilidad de ayudar a países menos capacitados a renegociar deudas en mejores condiciones. De hecho, esto ya sucedió entre México y Nicaragua.

Un tercèr paso implicaría ya la adopción de criterios comunes en las negociaciones con la banca internacional. Destaca por su importancia la necesidad de ponerse de acuerdo sobre una manera diferente de priorizar la utilización de las divisas, que dé preferencia a las importaciones necesarias para mantener la planta industrial, el empleo y el crecimiento -lo que constituye la mejor garantía de una capacidad de pago a mediano y largo plazos, y no sólo de la solución del problema de flujo de caja, al tiempo que contribuya a la superación de la recesión mundial- $y$, sin que esto implique el no pago de las deudas, vaya cubriendo el servicio que originan, de manera residual.

Otras medidas y soluciones podrian ser planteadas, sin duda, antes de llegar a sugerir una negociación o una moratoria conjunta, pero en lo que debe insistirse es en el hecho de que cualquiera que sea el grado de concertación que se plantee, ésta debe tener como principal fundamento el establecimiento de un compromiso verdadero y la manifestación de una voluntad política, sin los cuales la discusión de estas cuestiones difícilmente superará el nivel del ejercicio académico.

Recientemente, la vir Cumbre del Movimiento de Países No Alineados, realizada on Nueva Delhi del 7 al 11 de marzo, plantéó en su comunicado final la necesidad de llevar a cabo reformas profundas en el sistema financiero internacional, y con el ánimo de que esa solicitud no se convierta en una más de las que tradicionalmente plantea el mundo en desarrollo, en términos casi idénticos, se decidió la inmediata convocatoria de una reunión internacional sobre financiamiento del desarrollo. De la capacidad del Movimien- 
to de politizar y concientizar esa reunión, así como de acudir a ella con mayores niveles de información compartida y posiciones, si no comunes, al menos afines, puede depender el aprovechamiento del espacio negociador que, irónicamente, la actual crisis financiera internacional, le ha creado al mundo en desarrollo. La responsabilidad de América Latina en este esfuerzo, se insiste, es enorme, tanto por razones históricas como estructurales, y no debe ser menospreciada. De ahí el papel que una instancia política-económica tan latinoamericana como el seLA, tendría que desempeñar, si los gobiernos de la región estuvieran dispuestos no sólo a disfrutar de las ventajas transitorias a las que su endeudamiento externo dio lugar, sino a compartir el costo político (y aún económico) que puede implicar la construcción de un sistema donde los beneficios del progreso sean más permanentes y tengan por base, fundamentalmente, el esfuerzo nacional. 